\title{
STRENGTHENING OF CULTIVATOR PAWS WITH ELECTROSPARK DOPING
}

\author{
Sergey Strebkov, Alexey Slobodyuk, Andrey Bondarev, Andrey Sakhnov \\ Belgorod State Agricultural University named after V. Gorin, Russia \\ serwastr@gmail.com, aspl22@yandex.ru, av.bondarev@gmail.com, sakhnovav@mail.ru
}

\begin{abstract}
Currently, a serious increase in the reliability of structural elements allows manufacturers of equipment to routinely reduce the durability of individual elements to increase the level of sales. Maintainability is provided not by the constructive and technological capabilities of detecting and eliminating the failure by methods of repair and restoration, but by replacing with new parts. The main strategy of the dealer network to make a profit is determined by the sale of consumables and spare parts. Debugged in mass production manufacturing technology with a minimum cost does not provide modern methods of hardening in order to increase the durability of parts. It is a fact, that the farmers' interests are ignored in reducing the operating costs, including the cost of replacing the working bodies of the tillage machines. An increase in the resource can be achieved by controlling the process of wear by increasing the wear resistance. A way to increase durability is to strengthen the working edges of the working bodies of tillage machines during operation. This goal can be achieved by electrospark doping (ESD). As a strengthening technology, it is an economically viable and technologically promising solution for the possibility of increasing the resource. When performing the work, the following tasks were solved: 1. development of a technology for obtaining wear-resistant coatings on the surfaces of lancet paws with improved performance properties; 2. rationale for the choice of the material of the alloying electrode; 3 . carrying out operational evaluation of increase of the service life of the processed working bodies of soil-cultivating machines. Electric-spark hardening was performed with three materials: R5M6 (high speed steel), terminal electrode T-590 (an alloy of iron resistant to abrasive wear) and T15K6 (alloy of cobalt and carbides of titanium and tungsten). In conclusion, it should be noted that the best electrode material for hardening is the electrode rod T-590, which will reduce the wear rate by weight and the linear parameters three times in comparison with the untreated paws.
\end{abstract}

Keywords: cultivator, repair, strengthening, restoration, hoe.

\section{Introduction}

When cultivating crops, many tillage machines are used, such as cultivators, tillers, rippers, seeders and sowing complexes [1-3], the working bodies of which are lancet paws [1]. Lancet paws in operation are in direct contact with abrasive particles of the soil causing their intensive wear, reduction of sharpness of cutting edges, change of the form and the sizes. The process of operation of worn-out working bodies of tillage machines leads to a drop in the quality of the work performed, increase in the consumption of fuels and lubricants, disruption of agrotechnical terms of operations, increased downtime of equipment, direct and indirect costs, reducing the number of commercial products received.

Currently, a serious increase in the reliability of structural elements allows manufacturers of equipment to reduce the planned durability of individual elements to increase the level of sale. Maintainability is provided not by constructive and technological capabilities of failure detection and elimination by methods of repair or restoration, but by replacement with new parts. The main strategy of the dealer network for profit is the sale of consumables and spare parts. Well-established in mass production manufacturing technology with a minimum cost does not provide for modern methods of hardening in order to increase the durability of parts. The fact is ignoring the interests of agricultural enterprises in reducing the operating costs, including the cost of replacing the working bodies of tillage machines.

It is possible to increase the life of the pointed paws by controlling the wear process by increasing the wear resistance [3]. A way to increase the wear resistance is to strengthen the working edges of the working bodies of tillage machines [1-2], subjected to intensive wear in an abrasive environment, during operation.

To date, the most promising way to increase the wear resistance, and as a consequence the resource of the working bodies of tillage tools, is to strengthen their working edges in new or restored parts [2;3]. As reinforcing coating materials are used: sormayt, high-alloy cast iron and materials containing in their composition expensive and rare alloying elements - tungsten, molybdenum, chromium, cobalt, nickel, etc., which often leads to a significant rise in the cost of the working bodies. 
However, the analysis of modern technical literature [1-7] showed that at the present time due attention is not paid to the method of electrospark alloying (building, hardening) of parts. The method of electrospark doping (ESD) is cost-effective and technologically promising in solving the problems of increasing the performance of various machine parts and cutting tools subjected to intensive wear [8]. Due to the wide range of materials that can be used in electrospark alloying, participation of the interelectrode medium in the formation of wear-resistant surface layers, it is possible to widely change the mechanical, electrical, thermal, thermionic and other properties of the working surfaces of the restored parts [8;9].

The work is devoted to improve the life of the working bodies of tillage machines, particularly of the lancet paw cultivators, by improving the operational properties of the surface layer by the method of electric-spark processing.

When performing the work, the following tasks were solved.

1. Development of a technology for obtaining wear-resistant coatings on surfaces of lamellar paws with improved performance properties.

2. Justification of the choice of alloying electrode material.

3. Conduct an operational assessment of the increased service life of the treated working bodies of the tillage machines.

The object of the study was the patterns of the change in the resource of the lancet paws, depending on the electrode material and the doping modes of the lancet paws of the KPO-9 cultivator (the cultivator is secondary tillage, working width 9 meters).

The subject of the study is the operational properties of the coating layers on the worn surfaces obtained by means of the electric spark method of building on the cutting surfaces of the pointed paws of cultivators.

High yield of agricultural crops is impossible without different methods of tillage, because the quality of tillage greatly affects important indicators such as productivity, cost and efficiency of agricultural production [4].

\section{Materialsandmethods}

Currently, agriculture cannot be imagined without a variety of tillage tools. The most common type of devices for tillage on a par with the discs is the lancet paw. There are two main types of lancet paws - universal and flat-cutting, which differ structurally - the angle of elevation and the angle of the paw solution, and are designed for various operations in cultivation of crops.

For universal pointed paws, the greatest wear rate is characteristic of their socks. On different soils, the wear of the toe of the arched paws is 2.2...2.5 times the wings of the paws [5]. With the distance from the toe of the paw, the wear rate of the cutting edge of the paw decreases.

In order to increase the wear resistance of the lamella paws of tillage implements, it is necessary to use strengthening technologies for their restoration.

Currently, the repair industry has developed many technologies for surface hardening of parts. However, not all technologies are applicable for the lancet paws of tillage implements, which work under conditions of intensive abrasive wear with significant dynamic and shock loads.

There are various types of testing of the electric-spark method, which showed that the use of SHS electrodes in the process of applying the method of ESD hardening coatings, will allow to obtain coatings with a thickness of 5 to 200 microns, while the continuity of coatings can reach $100 \%$. These coatings are characterized by very high hardness (10-30 GPa), good adhesion to the surface being restored and significantly increase the wear resistance of the parts on the working surfaces on which they are applied. Resource hardened parts can be increased from 2 to 10 times.

As electrodes for electric-spark processing any conductive materials can be used, conditionally divided into 4 groups [6]. The main requirement for them is the conductivity of electric current. It has been established that to obtain wear-resistant coatings, materials belonging to the first and second group should be used (iron-based alloys with special properties, including ferroalloys; alloyed steels; cast irons (ductile, gray, special); carbides, nitrides, borides, and other solid compounds of refractory metals (Cr, Mo, Ti, W, Ta, Zr, V, Nb); tungsten-containing hard alloys; tungsten-free hard alloys. 
There are two approaches to the methods of restoring cultivator paws:

- applying a layer on the back (bottom) side while ensuring the effect of self-sharpening [7];

- applying a layer on the front (top) side of the paws [7].

Taking into account the insignificant wear-compensating layer of the metal obtained by the electric-spark treatment, the paws under study were strengthened on the most wearing face.

Operational tests of reinforced articulated paws were carried out on the fields of the Educational And Scientific Innovation Center "Agrotechnopark" of the Belgorod district of the Belgorod region. Characteristics of the soil: type - black earth; density $-1200 \ldots 1250 \mathrm{~kg} \cdot \mathrm{m}^{-3}$; humidity during the test period $18 \ldots . .23 \%$. Cultivator KPO-9, aggregated with a tractor Valtra-T270. The following types of work were carried out: pre-sowing soil preparation and cultivation of unoccupied vapors.

During the tests, we checked the change in the linear dimensions (wear) of the nose of the lamellae, the width of their wings, and the mass of the paw. This is due to the fact that these criteria are fundamental when cupping paws [8;9]. The cultivator paws studied were installed in the first row of the cultivator. Lancet paws that walked along the tractor track were not investigated, since they are subject to loads that are sharply different from the legs that do not follow the track.

To measure the paw wear, a ShTs-I - 250-0.05 GOST 166-89 caliper with a measurement error of no more than $0.05 \mathrm{~mm}$ and a laboratory balance SARTOGOSM VLT 510-P were used.

\section{Resultsanddiscussion}

During the research, the following indicators were measured:

- mass of the paw before coating,

- mass of the deposited material,

- mass of the paw after field work,

- linear dimensions of the paw before the start of the field work (distance from the sock to the mounting hole $A$, paw width $L a$ ),

- linear dimensions of the legs after completion of the field work (distance from the sock to the mounting holes $A$, width of paws $L a$ ) (Figure 1-3).

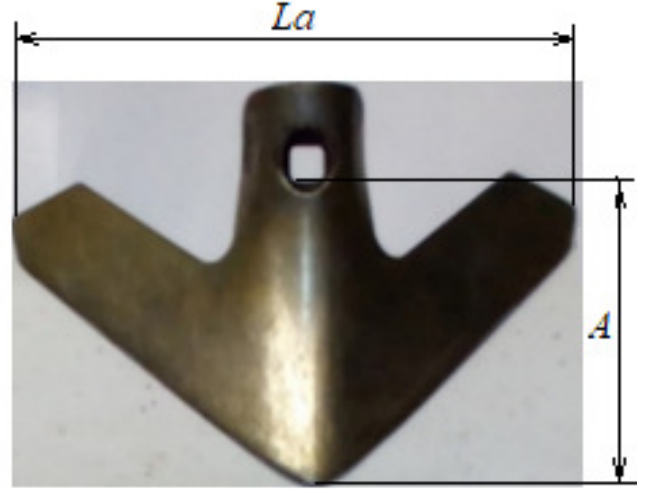

Fig. 1. Lancet paw before coating (control)

Electric spark hardening of the worn out lacquerous paw layer was carried out in three materials: R5M6 (high-speed steel), electrode core T-590 (iron alloy resistant to abrasive wear) and T15K6 (titanium-tungsten alloy) simultaneously with the hardened on the cultivator installed and serial nonreinforced paws. Measurement of the paw wear was carried out at the end of the field work. Before the study, the articulated legs were removed from the cultivator and were well cleaned of dirt.

The weight of the lancet paws before coating varied in the range from $419.70 \mathrm{~g}$ to $446.18 \mathrm{~g}$, size $\mathrm{A}$ - from the toe of the paw to the hole - from $106.60 \mathrm{~mm}$ to $110.70 \mathrm{~mm}$, the grip width of the La paw from $206.20 \mathrm{~mm}$ to $209.70 \mathrm{~mm}$ (Tables 1,2 ). 


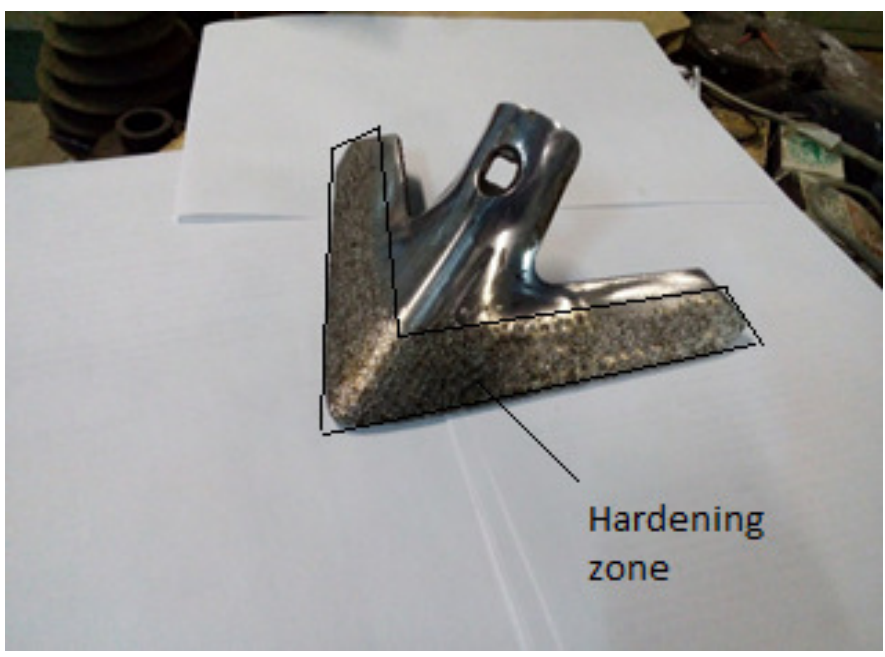

Fig 2.Lancet paw after coating

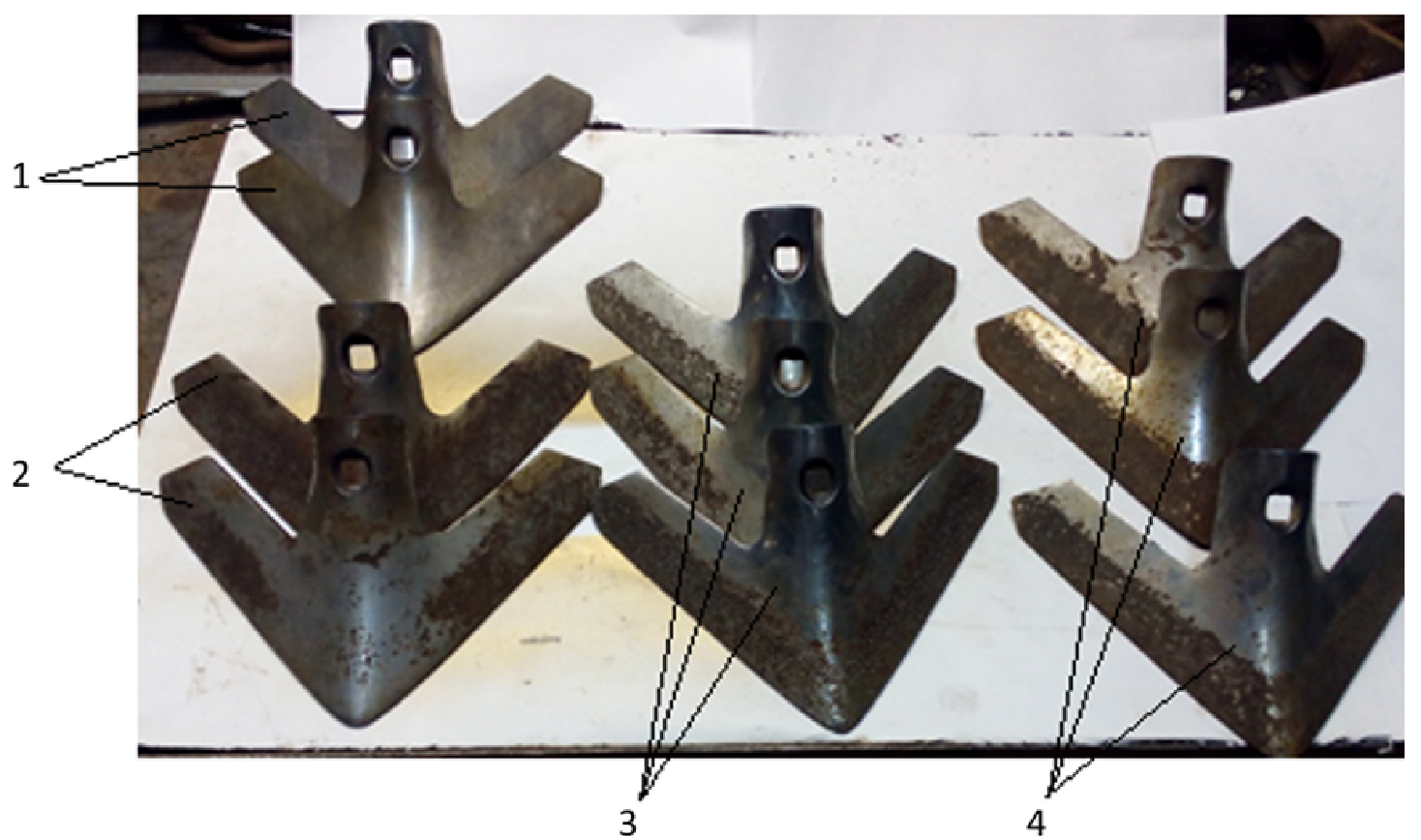

Fig. 3. Lancet paws after field work, reinforced with various electrodes:

1 - control; 2 - R5M6; 3 - T15K6; 4 - T-590

Table 1

Research results mass characteristics of lancet paws

\begin{tabular}{|c|c|c|c|c|c|c|c|c|c|}
\hline \multirow[b]{2}{*}{$\frac{\bar{d}}{\bar{d}}$} & \multirow[b]{2}{*}{ Group } & \multicolumn{2}{|c|}{ Pawweight } & \multirow[b]{2}{*}{ 苞 } & \multirow[b]{2}{*}{ 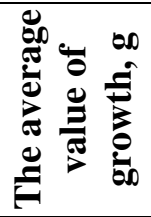 } & \multirow[b]{2}{*}{ 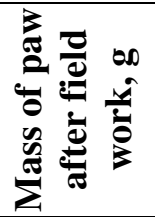 } & \multirow[b]{2}{*}{ है } & \multirow[b]{2}{*}{ 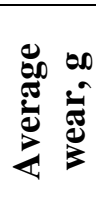 } & \multirow[b]{2}{*}{ 窇 } \\
\hline & & 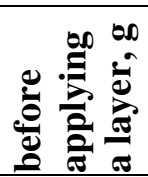 & 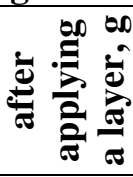 & & & & & & \\
\hline 01 & \multirow{4}{*}{ 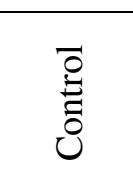 } & 419.70 & 419.70 & 0.00 & \multirow[t]{4}{*}{5} & 412.86 & 6.84 & \multirow{4}{*}{5.49} & \multirow{4}{*}{2.90} \\
\hline 02 & & 428.22 & 428.22 & 0.00 & & 424.76 & 3.46 & & \\
\hline 03 & & 430.65 & 430.65 & 0.00 & & 420.71 & 9.94 & & \\
\hline 04 & & 433.59 & 433.59 & 0.00 & & 431.86 & 1.73 & & \\
\hline 11 & \multirow{3}{*}{ 离 } & 428.59 & 429.13 & 0.54 & \multirow{3}{*}{0.64} & - & - & \multirow{3}{*}{1.25} & \multirow{3}{*}{0.39} \\
\hline 12 & & 428.66 & 429.56 & 0.90 & & 428.71 & 0.85 & & \\
\hline 13 & & 438.32 & 438.95 & 0.63 & & - & - & & \\
\hline
\end{tabular}


Table 1 (continued)

\begin{tabular}{|c|c|c|c|c|c|c|c|c|c|}
\hline \multirow[b]{2}{*}{ 离 } & \multirow[b]{2}{*}{ Group } & \multicolumn{2}{|c|}{ Pawweight } & \multirow[b]{2}{*}{$\sum_{0}^{\infty}$} & \multirow[b]{2}{*}{ 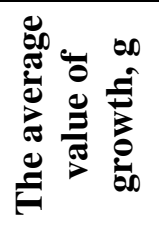 } & \multirow[b]{2}{*}{ 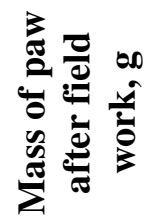 } & \multirow[b]{2}{*}{$\stackrel{00}{\ddot{E}}$} & \multirow[b]{2}{*}{ 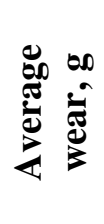 } & \multirow[b]{2}{*}{ 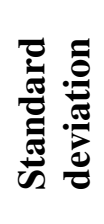 } \\
\hline & & 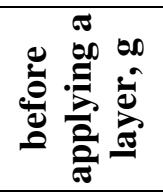 & مo & & & & & & \\
\hline 14 & & 423.39 & 423.86 & 0.47 & & 422.22 & 1.64 & & \\
\hline 21 & \multirow{4}{*}{$\sum_{\substack{0 \\
n}}^{n}$} & 444.57 & 446.80 & 2.23 & \multirow{4}{*}{1.93} & 442.88 & 3.92 & \multirow{4}{*}{3.90} & \multirow{4}{*}{1.72} \\
\hline 22 & & 430.74 & 432.81 & 2.07 & & 431.49 & 1.32 & & \\
\hline 23 & & 442.43 & 444.01 & 1.58 & & 437.55 & 6.46 & & \\
\hline 24 & & 429.02 & 430.85 & 1.83 & & - & - & & \\
\hline 31 & \multirow{4}{*}{$\begin{array}{l}\stackrel{0}{\mathscr{n}} \\
\stackrel{\mathfrak{n}}{E}\end{array}$} & 446.18 & 447.29 & 1.11 & \multirow{4}{*}{1.32} & 444.14 & 3.15 & \multirow{4}{*}{1.94} & \multirow{4}{*}{0.81} \\
\hline 32 & & 434.30 & 436.08 & 1.78 & & 434.23 & 1.85 & & \\
\hline 33 & & 442.23 & 443.48 & 1.25 & & - & - & & \\
\hline 34 & & 443.17 & 444.31 & 1.14 & & 443.50 & 0.81 & & \\
\hline
\end{tabular}

The study showed that the mass increment varied over a wide range: from $0.64 \mathrm{~g}$ by the T-590 electrode to $1.93 \mathrm{~g}$ of the R6M5 alloy.

Table 2

Research results linear characteristics of lancet paws

\begin{tabular}{|c|c|c|c|c|c|c|c|c|c|c|c|}
\hline \multirow[b]{2}{*}{ 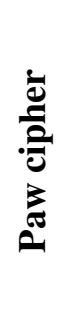 } & \multirow[b]{2}{*}{ 总 } & \multicolumn{5}{|c|}{ Size $A, \mathbf{m m}$} & \multicolumn{5}{|c|}{ Size $L a, \mathrm{~mm}$} \\
\hline & & 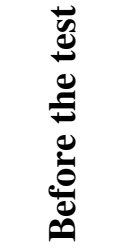 & 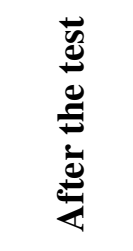 & 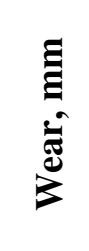 & 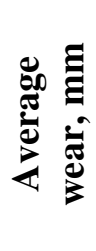 & 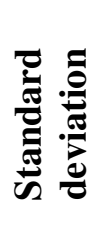 & 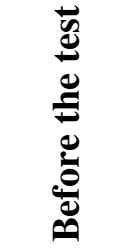 & 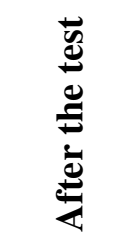 & 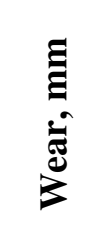 & 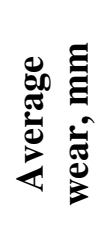 & 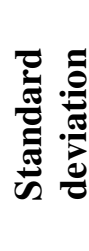 \\
\hline 01 & \multirow{4}{*}{$\begin{array}{l}\overline{0} \\
\text { : } \\
0 \\
0\end{array}$} & 106.60 & 104.20 & 2.40 & \multirow{4}{*}{1.66} & \multirow{4}{*}{1.01} & 208.90 & 208.50 & 0.40 & \multirow{4}{*}{0.27} & \multirow{4}{*}{0.13} \\
\hline 02 & & 108.60 & 107.70 & 0.90 & & & 208.60 & 208.40 & 0.20 & & \\
\hline 03 & & 107.00 & 104.05 & 2.95 & & & 208.70 & 208.30 & 0.40 & & \\
\hline 04 & & 107.50 & 107.10 & 0.40 & & & 208.60 & 208.50 & 0.10 & & \\
\hline 11 & \multirow{4}{*}{$\begin{array}{l}8 \\
\text { r } \\
n\end{array}$} & 108.70 & - & - & \multirow{4}{*}{0.50} & \multirow{4}{*}{0.10} & 206.20 & - & - & \multirow{4}{*}{-0.53} & \multirow{4}{*}{0.08} \\
\hline 12 & & 108.00 & 107.60 & 0.40 & & & 208.70 & 209.30 & -0.60 & & \\
\hline 13 & & 109.30 & & & & & 208.40 & - & - & & \\
\hline 14 & & 106.90 & 106.30 & 0.60 & & & 209.20 & 209.65 & -0.45 & & \\
\hline 21 & \multirow{4}{*}{$\sum_{\substack{n \\
0}}^{n}$} & 110.40 & 109.10 & 1.30 & \multirow{4}{*}{1.37} & \multirow{4}{*}{0.49} & 208.60 & 209.00 & -0.40 & \multirow{4}{*}{-0.48} & \multirow{4}{*}{0.14} \\
\hline 22 & & 109.10 & 108.40 & 0.70 & & & 206.80 & 207.50 & -0.70 & & \\
\hline 23 & & 110.20 & 108.10 & 2.10 & & & 208.40 & 208.75 & -0.35 & & \\
\hline 24 & & 108.40 & - & - & & & 209.70 & - & - & & \\
\hline 31 & \multirow{4}{*}{ 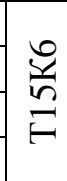 } & 110.70 & 109.00 & 1.70 & \multirow{4}{*}{0.82} & \multirow{4}{*}{0.59} & 208.60 & 209.45 & -0.85 & \multirow{4}{*}{-0.98} & \multirow{4}{*}{0.09} \\
\hline 32 & & 109.00 & 108.55 & 0.45 & & & 209.00 & 210.00 & -1.00 & & \\
\hline 33 & & 110.30 & - & - & & & 208.60 & - & - & & \\
\hline 34 & & 110.60 & 110.30 & 0.30 & & & 208.60 & 209.70 & -1.10 & & \\
\hline
\end{tabular}

A machine-tractor unit consisting of a Valtra T270 tractor and a KPO-9 cultivator was treated with 130 hectares. Immediately after the operation of the cultivator in the field, the lancet paws were removed from it and cleaned of dirt, the measurements of linear dimensions and mass were repeated (Tables 1, 2).

According to the data obtained, the minimum wear of the lamellar paw was obtained by doping the surface layer with the T-590 electrode rod, the maximum - on the control sample and doping with high-speed steel R6M5. The wear rate has also changed accordingly from $0.51 \mathrm{~g} \cdot \mathrm{ha}^{-1}$ for the paws reinforced with T-590 to $2.24 \mathrm{~g} \cdot \mathrm{ha}^{-1}$ for the standard paws of the control group. 
As it turned out during the field tests, the width of the lancet-foot grip may not only decrease due to normal wear, but also increase. The increase in the width of the grip can be explained by the operation of the paw in extreme conditions that are not normal for it, for example, the width may increase due to plastic deformation when hitting an obstacle or when the cultivator is sharply lowered onto a dirt road at the edge of the field.

The data on linear wear of the distance from the toe of the paw to the mounting hole (Table 2) are of the greatest interest.Analysis of the data showed that the maximum reduction in size A (Table 2) and as a consequence the maximum wear occurred on the "control" pointed legs, which were not subjected to electrospray processing. In this case, the best wear-resistant characteristics according to the results of the field tests have lancet paws, hardened with the help of electrodes T-590.

\section{Conclusions}

In conclusion it is worth noting that, based on an analysis of the studies conducted on the totality of the changes in the mass and linear dimensions, it is clear that the electrospark alloying method increases the service life of the pointed paws compared to untreated paws, while the best electrode material for hardening is the T-590 electrode rod, which will provide threefold decrease in the wear rate in terms of weight and linear indexes.

\section{References}

[1] Hanna H.M., Hartzler R.G., Erbach D. C. High-speed Cultivation and Banding for Weed Management in No-Tillage Corn. Applied Engineering in Agriculture,vol.16, 2000 pp.359-365;

[2] Filip N., Simu I., Airinei D. Some aspects regarding the precision farming concept used in the harvesting process, Actual tasks on agricultural engineering, Vol. 37, 2009.Opatija, Croatia, pp. 213-222;

[3] Stewart L.T., Jonson J.D. Determining optimum burn-in and replacement times using Bayessian decision theory -"IEEE Transaction on Reliability". Vol. R-21, 1972, No.3;

[4] Biswas, H.S. Performance Evaluation and optimization of straight blades for shallow tillage and weeding in black soils. Agric. Mech. in Asia, Africa and Latin America, 24(4), 2009. pp. 19-22;

[5] Galat U.N., Ingale A.N. Failure Investigation \& Analysis of Agricultural 9 Tyne Cultivator Used In Various Soil Condition. International Journal on Recent and Innovation Trends in Computing and Communication. Volume: 4 Issue: 1, 2016, pp. 173-179;

[6] Tutunaru L.F., Nagy E.M., Coţa C. Influence of tillage tools cutting edge wear over technical and economic indicators. INMATEH - Agricultural Engineering, vol.44, No.3, 2014, pp. 5-12;

[7] Zhang J., Kushwaha R.L. Wear and draft of cultivator sweeps with hardened edges. Canadian Agricultural Engineering, 37 (1), 2004, pp.41- 47;

[8] Стребков С.В., Слободюк А.П., Бондарев А.В. Восстановление работоспособности деталей зарубежной сельскохозяйственной техники (Restoration of working capacity of parts of foreign agricultural machinery). Materials of the International distance research and practice conference "Important directions of scientific investigations of the XXIth century: theory and practice": collection of research papers, Voronezh, Russia, 5 (2014), pp. 268-272. (In Russian);

[9] Стребков С.В., Слободюк А.П., Бондарев А.В. Восстановление комплектующих импортной техники (Recovery of components imported machinery). Moscow, Proceedings GOSNITI. - 2014 - T.117, ch. 1. (In Russian). 